https:// doi.org/10.15407/mineraljournal.41.02.026

УДК $549.3: 523.681 .8$

\title{
Е.П. Гуров, В.В. Пермяков
}

Институт геологических наук НАН Украины

01601, г. Киев, Украина, ул. Олеся Гончара, 55-б

E-mail: yevgeniy.gurov@gmail.com; 0673866227@ukr.net

\section{ХРОМФЕРИД В РАСПЛАВНЫХ ИМПАКТИТАХ КРАТЕРА ЭЛЬГЫГЫТГЫН (ЧУКОТКА, РФ)}

\begin{abstract}
Хромферид установлен в результате электронно-микроскопического изучения ударнорасплавленных пород импактного кратера Эльгыгытгын на Чукотке. Эта структура диаметром 18 км и возрастом 3,6 млн лет образована в толще вулканогенных пород мелового возраста в центральной части Чукотского полуострова (РФ). На современном уровне эрозионного среза кратера расплавные импактиты распространены в переотложенном виде в составе террас кратерного озера. Они представлены массивными пузырчатыми породами со стекловатой матрицей и многочисленными включениями обломков ударнометаморфизованных пород и минералов мишени кратера. Хромферид кристаллизуется в контракционных трещинах в стекловатой матрице пород, а также на внутренней поверхности газовых пузырей. Эти условия выделения минерала свидетельствуют о его позднем образовании на стадии затвердевания и охлаждения ударного расплава. Состав хромферида из расплавных импактитов соответствует составу эталонного минерала и кристаллохимической формуле $\mathrm{Fe}_{3,0} \mathrm{Cr}_{0,4}$ или $\mathrm{Fe}_{1,5} \mathrm{Cr}_{0,2}$. Ранее в ходе геохимического изучения состава расплавных импактитов и пород мишени кратера Эльгыгытгын было установлено значительное относительное обогащение ударнорасплавленных пород хромом за счет вещества ударника, в связи с чем вероятным основным источником хрома для образования минерала послужило вещество кратерообразующего метеорита. Установление хромферида в кратере Эльгыгытгын - его первая находка в ударнорасплавленных породах земных импактных структур.
\end{abstract}

Ключевые слова: хромферид, импактный кратер Эльгыгытгын, ударнорасплавленная порода, стекловатая матрица, контракционная трещина.

Введение. Акцессорная минерализация хромферида установлена в составе ударнорасплавленных пород кратера Эльгыгытгын. Впервые хромферид как новый минеральный вид был определен и описан в породах из золоторудных месторождений на Южном Урале и в Средней Азии $[5,6]$. Хромферид - это упорядоченный нестехиометрический твердый раствор состава: $\mathrm{Fe}_{1,5} \mathrm{Cr}_{(0,5-x)}$, основой кристаллической структуры которого служит несовершенная кубическая ячейка с параметром $a_{0}=2,859 \pm$ $\pm 0,005 \AA[6,17]$.

Кратер Эльгыгытгын расположен в центральной части Чукотского полуострова на северо-востоке России. Впервые депрессия озера Эльгыгытгын была открыта С.В. Обручевым в 1933 году и предварительно опре-

(C) Е.П. ГУРОВ, В.В. ПЕРМЯКОВ, 2019 делена как гигантская вулканическая структура [7]. Возможность метеоритного происхождения структуры впервые была высказана Некрасовым и Раудонисом [4], однако в результате неудавшихся поисков коэсита в шлифах вулканических пород вала кратера эти исследователи вернулись к представлениям о ее вулканической природе [4]. Тем не менее, благодаря этой работе, структура Эльгыгытгын была внесена в список вероятных метеоритных кратеров на поверхности Земли [3]. На основании изучения космических снимков структуры Р. Дитц и Дж. Макхоун [11] пришли к выводу о том, что Эльгыгытгын - крупнейший молодой метеоритный кратер на поверхности Земли. Было высказано предположение о кратере Эльгыгытгын как вероятном источнике австрало-азиатских тектитов [10].

ISSN 2519-2396. Mineral. Journ. (Ukraine). 2019. 41, No 2 
Импактное происхождение кратера Эльгыгытгын было доказано в результате установления ударнометаморфизованных и ударнорасплавленных пород в этой структуре [1]. Определение изотопного возраста импактитов кратера, равного 3,50 \pm 0,50 млн лет [17], дало возможность опровергнуть предположение Р. Дитца [10] о кратере Эльгыгытгын как возможном источнике австрало-азиатских тектитов.

С конца 90-х годов XX века кратер Эльгыгытгын служит объектом интенсивных международных научных исследований, в которых принимали участие ученые из Венского университета (Австрия), Аляскинского и Массачусетского университетов (США), Берлинского университета Гумбольдта и Института Альфреда Вегенера в Потсдаме (ФРГ), Северо-Восточного комплексного научно-исследовательского института РАН и некоторых других организаций. Важной вехой в изучении кратера стало бурение в 2009 г. со льда озера Эльгыгытгын скв. 5011-3 глубиной 513 м по программе International Continental Scientific Drilling Program, проведенное под руководством проф. Х. Keберля из Венского университета (Австрия) [20].

Несмотря на исчерпывающие доказательства метеоритного происхождения кратера Эльгыгытгын, ученые из Северо-Восточного комплексного НИИ РАН продолжают развивать экзотические гипотезы о вулканотектоническом или вулканическом происхождении этой структуры в результате "эндогенного импактогенеза" [8, 9].

Импактный кратер Эльгыгытгын диаметром 18 км имеет вид блюдцеобразной депрессии, окруженной приподнятым кольцевым валом высотой до 200-300 м над ее дном. Центральную часть депрессии занимает озеро Эльгыгытгын диаметром 12 км, окруженное комплексом озерных террас высотой до 80 м [1, 2].

Кратер Эльгыгытгын расположен в пределах Охотско-Чукотского вулканического пояса в толще вулканогенных пород позднемелового возраста, среди которых преимущественно распространены игнимбриты, лавы и туфы риолитов. По этим данным, кратер Эльгыгытгын - единственная импактная структура на поверхности Земли, образованная в вулканогенных породах кислого состава [1, 14, 15, 20]. Уточненный возраст ударнорасплавленных пород кратера по данным ${ }^{40} \mathrm{Ar} /{ }^{39} \mathrm{Ar}$ метода равен $3,58 \pm 0,05$ млн лет [21].
Импактные породы в кратере на современном эрозионном уровне сохранились в переотложенном виде в озерных террасах $[1,2]$. Импактиты представлены ударнорасплавленными породами, стекловатыми бомбами аэродинамической формы и ударнометаморфизованными лавами и туфами мишени. Источником повсеместно распространенных в террасовых отложениях стекловатых бомб и ударнометаморфизованных пород служил покров выбросов зювитов, который к настоящему времени полностью эродирован. Расплавные импактиты, образующие локальные скопления глыб и обломков в террасовых отложениях, - это продукты разрушения отдельных потоков ударного расплава, застывшего на внутренних склонах кратера [2, 14]. В коренном залегании импактные породы в центральной части структуры установлены в скв. 5011-3, где зювиты и брекчии залегают под толщей озерных осадков в интервале 315-517 м [20].

Материалы и методы исследования. Хромферид был установлен в ходе электронно-микроскопического изучения двух образцов расплавных импактитов из террасовых отложений южного берега озера Эльгыгытгын. Эти исследования охватывали изучение микроструктур пород, химического состава стекловатой матрицы и кристаллитов, а также минералов включений и следов воздействия на них высокотемпературного ударного расплава.

Исследования выполнены на сканирующем электронном микроскопе $J E O L J S M-6490 L V$ с рентгеновской спектрометрической системой INCA Energy + (Oxford Instruments). Система состоит из энергодисперсионного спектрометра (ЭДС) INCA-act с аналитическим силиконовым детектором $(A D D)$ и волнового дисперсионного спектрометра (ВДС) INCA WAWE 500 с программным обеспечением. Исследования проведены в фазоконтрастном режиме отраженных электронов (BSEI).

Результаты исследований. Расплавные импактиты состоят из пузырчатого девитрифицированного стекла, содержащего многочисленные включения обломочных зерен кварца, диаплектового кварцевого стекла с коэситом, лешательерита, полевых шпатов, а также редких зерен рудных и акцессорных минералов. В матрице заключены газовые пузыри округлой и неправильной формы, размеры которых колеблются от 10-20 до 100-200 мКм (рис. 1, a). Внутренняя поверхность пузырей покрыта 

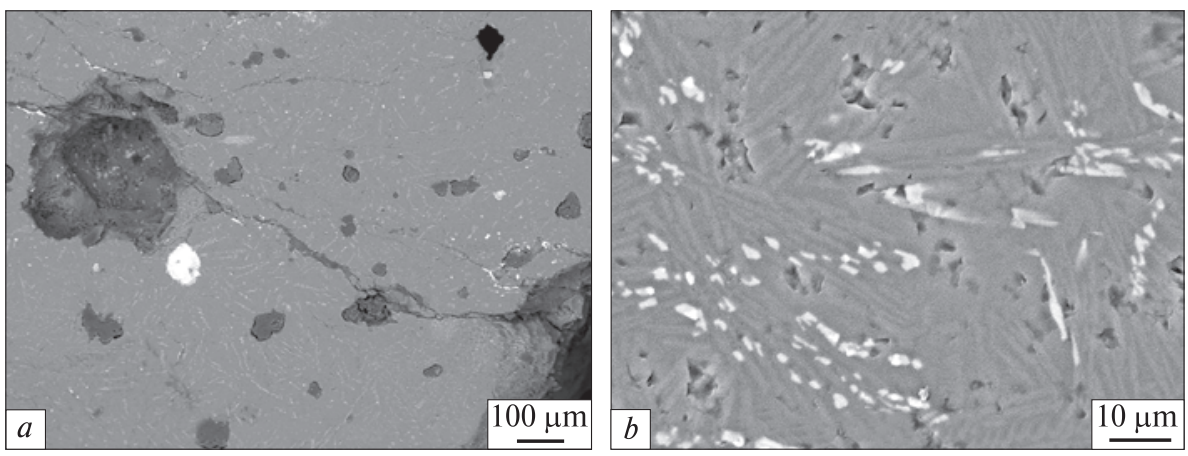

Puc. 1. Электронномикроскопические снимки в отраженных электронах (BSIE) ударнорасплавленной породы кратера Эльгыгытгын (обр. Е-900-12): $a$ - газовые пузыри в девитрифицированной матрице ударнорасплавленной породы. Агрегаты хромферида (светлые, справа внизу и слева вверху снимка) в контракционных трещинах породы. Светлое овальное зерно (слева от центра) представлено резорбированным цирконом; $b-$ скелетные длиннопризматические кристаллиты гиперстена (светлые) и удлиненные таблитчатые кристаллиты полевого шпата в девитрифицированной матрице ударнорасплавленной породы

Fig. 1. Back-scattered electron images of impact melt rock from the El'gygytgyn crater (sample E-900-12): $a-$ gas vesicles in devitrified glassy matrix of impact melt rock. Aggregates of chromferide (light in the lower right and upper left parts of image) occur in contraction cracks. Light oval clast (left of center) is resorbed grain of zircon; $b-$ skeletal long-prismatic crystallites of hypersthene (light) and lamellar crystallites of feldspar in devitrified matrix of impact melt rock
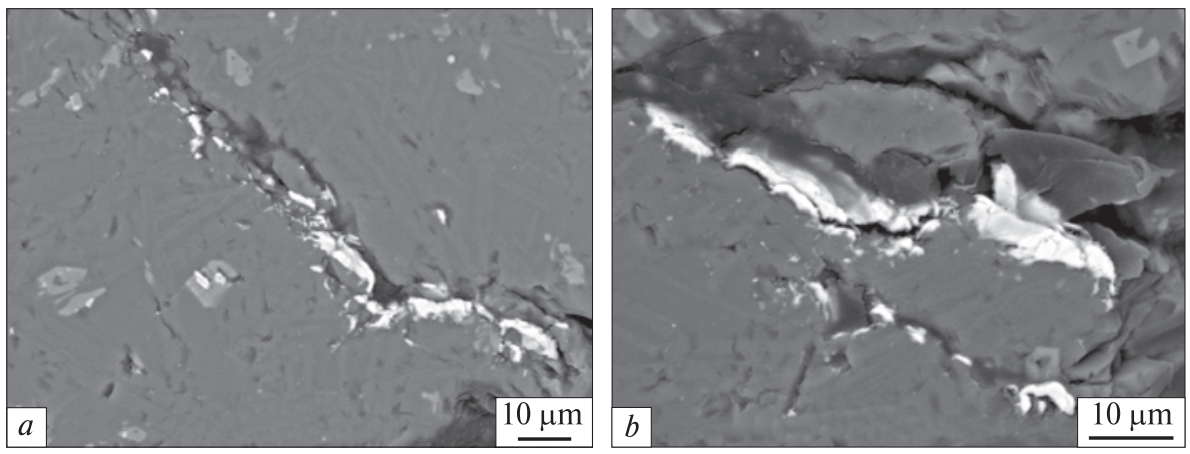

Puc. 2. Хромферид в контракционных трещинах в стекловатой матрице ударнорасплавленной породы (обр. Е-900-12): $a$ - выделения хромферида выполняют участки трещин и образуют отдельные зерна на их поверхности; $b$ - трещина в агрегате хромферида (слева от центра изображения) свидетельствуют о продолжающемся расширении контракционной трещины после кристаллизации минерала

Fig. 2. Chromferide in contraction cracks of glassy matrix of impact melt rock (sample E-900-12): $a$ - aggregations of chromferide fill the cracks and form separate grains on their surface; $b-$ the crack in the aggregate of chromferide (left from center of the image) testifies to continuation of crack expansion after crystallization of the mineral

сложными агрегатами кристаллитов полевого шпата и наиболее позднего титаногематита, образующего идиоморфные кристаллиты изометрического габитуса. Внутри некоторых пузырей установлены реликтовые частицы палеофлоры, частично сохраняющие особенности морфологии и состава исходных фрагментов растений [16]. Матрица представлена девитрифицированным стеклом, состоящим из сноповидных и веерообразных агрегатов пластинчатых кристаллитов калиевого андезин-олигоклаза $\mathrm{Ab}_{(56-61)} \mathrm{An}_{(26-29)} \mathrm{Or}_{(10-16)}$ и удлиненнопризматических скелетных кристаллитов гиперстена $\mathrm{En}_{(56-64)} \mathrm{Fs}_{(33-43)} \mathrm{Wo}_{)(2-3)}$ (рис. 1, b).
В стекловатой матрице наблюдаются редкие контракционные трещины неправильной формы толщиной от $1-2$ до 8-12 мкм.

Хромферид наблюдается в открытых контракционных трещинах в стекловатой матрице, где он представлен в виде плотных агрегатов, заполняющих отрезки трещин длиной до 10-20 мкм (рис. 2, a). Форма и размеры (1-2 до 5-6 мкм) этих выделений минерала определены формой заполняемых трещин и их шириной. Кроме того, на внутренней поверхности некоторых трещин замечены отдельные зерна хромферида неправильной формы, реже его пластинчатые выделения (рис. 2, b). 

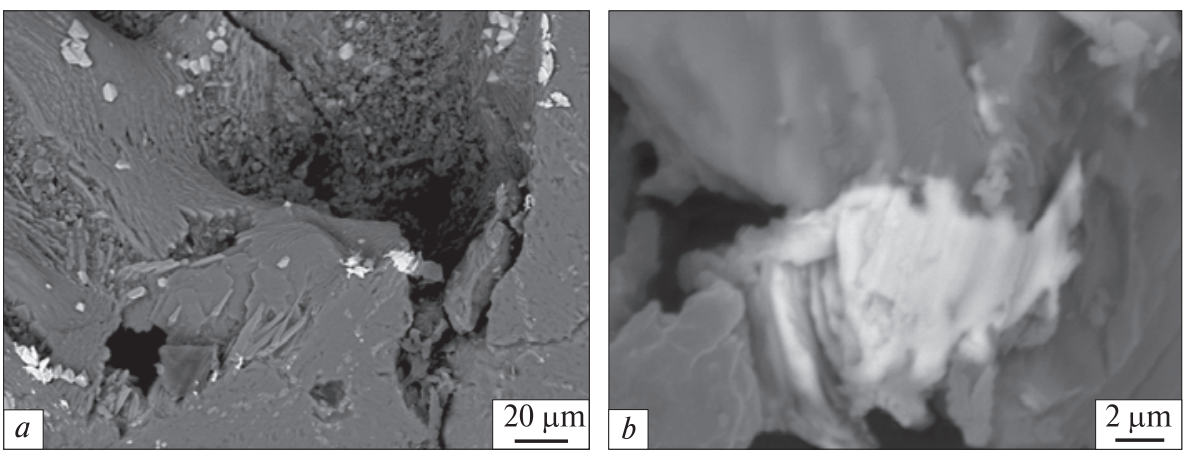

Puc. 3. Выделения хромферида в газовых пузырях ударнорасплавленной породы (обр. Е-900-12): $a-$ агрегаты хромферида на внутренней поверхности пузыря в стекловатой матрице. Внутреннюю поверхность пузыря выстилают пластинчатые изогнутые кристаллиты полевого шпата. Хромферид образует зерна и агрегаты на внутренней поверхности пузыря (светлые, в центре, в верхней правой и нижней левой частях изображения). Идиоморфные изометрические кристаллиты титаногематита (светло-серые, в верхней части) часто кристаллизуются в тесной пространственной связи с хромферидом (в левой нижней части); $b-$ выделение хромферида пластинчатого строения на внутренней поверхности пузыря

Fig. 3. Aggregations of chromferide in gas bubbles of impact melt rock (sample E-900-12): $a$ - grains of chromferide on the inner surface of the bubble in glassy matrix. The inner surface of the bubble is linked with curved plate crystallites of feldspar. Grains and aggregations of chromferide (light, in center, in upper right, and lower left parts of image). Idiomorphic isometric crystallites of titanium hematite (light grey, in the upper part of image), occasionally crystallize in close spatial connection with chromferide (lower left part of image); $b$ - lamellar structure of chromferide aggregation on the inner surface of the bubble

Вторая форма выделений хромферида представлена зернами или агрегатами зерен на внутренней поверхности газовых пузырей. Размеры зерен минерала составляют от 2-3 до 1012 мкм. Наблюдается пространственная связь выделений хромферида с идиоморфными кристаллитами позднего титаногематита (рис. $3, a$ ). В редких случаях зерна хромферида зафиксированы на внутренней поверхности газовых пузырей, содержащих частицы палеофлоры. Выделения хромферида на внутренней поверхности пузырей обнаруживают пластинчатое строение с толщиной индивидуальных ламелей около 1 мкм (рис. 3, b). Форма зерен и агрегатов хромферида, образованного в газовых пузырях, определяется их кристаллизацией в условиях свободного пространства. Важно отметить, что пластинчатое строение характерно для выделений хромферида из золото- рудных месторождений на Южном Урале и в Средней Азии [5, 6].

Состав хромферида приведен в таблице. Главные элементы минерала представлены железом и хромом с атомным отношением $\mathrm{Fe} / \mathrm{Cr}$ от 6,5 до 7,4 при среднем значении 7,0, что соответствует этому соотношению в эталонном хромфериде [6]. В составе некоторых зерен изученного хромферида установлено содержание до 0,15 мас. \% никеля. Примесь силиция в некоторых анализах предположительно может быть связана с влиянием матрицы. Для сравнения в таблице приведен состав эталонного хромферида из золоторудного месторождения Кумак на Южном Урале [5]. Формула хромферида из кратера Эльгыгытгын: $\mathrm{Fe}_{3,0} \mathrm{Cr}_{0,4}$ или $\mathrm{Fe}_{1,5} \mathrm{Cr}_{0,2}$. Формула эталонного хромферида: $\mathrm{Fe}_{3} \mathrm{Cr}_{1-x}$, где $x=0,6$ [5], или $\mathrm{Fe}_{1,5} \mathrm{Cr}_{0,5-x}, x=0,3$, при атомном отношении $\mathrm{Fe} / \mathrm{Cr}=\sim 7,0[6,18]$.

Состав хромферида из кратера Эльгыгытгын (1, 2, ЭДС данные) и золоторудного месторождения на Южном Урале (3) Composition of chromferide from El'gygytgyn crater (1, 2, EDS data), and from golden ore deposit in the Southern Ural (3)

\begin{tabular}{|c|c|c|c||c|c|c|c|}
\hline Компонент & 1 & 2 & 3 & Компонент & 1 & 2 & 3 \\
\cline { 4 - 7 } $\mathrm{Fe}$ & 86,85 & 87,00 & 88,91 & $\mathrm{Si}$ & 1,29 & - & - \\
$\mathrm{Cr}$ & 11,65 & 12,98 & 11,30 & $\Sigma$ & 99,79 & 99,98 & 100,21 \\
\hline
\end{tabular}

П р и м е ч а н и е. 1 - обр. Е-900-12, среднее по 5 анализам; 2 - обр. Е-900-1, среднее по 4 анализам; 3 хромферид, по [6].

N o t e. 1 - sample E-900-12, average of 5 analyzes; 2 - sample E-900-1, average of 4 analyzes; 3 - chromferide by [6]. 
Заключение. Акцессорная минерализация хромферида установлена в составе расплавных импактитов из кратера Эльгыгытгын. Это первая находка минерала в породах импактных структур.

В ударнорасплавленных породах кратера Эльгыгытгын хромферид кристаллизуется в контракционных трещинах или на внутренней поверхности газовых пузырей. Контракционные трещины образуются в стекловатой матрице после полного затвердевания пород в ходе дальнейшего понижения их температуры. Температура образования хромферида в расплавных импактитах может быть приблизительно оценена $\sim 400{ }^{\circ} \mathrm{C}$, по аналогии с температурой кристаллизации этого минерала из золоторудных месторождений Урала и Средней Азии [6]. Эти исследователи предполагают узкий температурный интервал кристаллизации хромферида, а также возможное относительное увеличение содержания хрома в его составе при повышении температуры образования. Так как атомное отношение $\mathrm{Fe} / \mathrm{Cr}$ в хромфериде из расплавных импактитов близко соответствует этому отношению в эталонном хромфериде, температурные условия его кристаллизации в контракционных трещинах ударнорасплавленных пород предположительно были близкими к значениям температуры образования минерала в золоторудных месторождениях [6].

Изучение минералогии и петрографии ударнорасплавленных пород кратера Эльгыгытгын не выявило в них следы гидротермальных изменений $[1,14,22]$. В связи с этим предполагается, что кристаллизация хромферида происходила из газовой фазы на стадии охлаждения затвердевающего потока расплавных импактитов. Форма пластинчатых зерен хромферида, образованных внутри газовых пузырей, определяется их образованием в условиях свободного пространства.

В результате геохимического исследования ударнорасплавленных пород из террасовых отложений кратера Эльгыгытгын установлено значительное обогащение их состава хромом, по сравнению с содержанием этого элемента в вулканогенных породах мишени, что послужило основанием для заключения о вероятном ахондритовом (уреилитовом) составе кратерообразующего астероида [2, 14, 24]. Капусткина и соавторы [19] определили слабое обогащение импактных стекол и ударнорасплавленных пород иридием, по сравнению с вулканитами мишени, и также предположили ахондритовый состав ударника в подтверждение выводов работы [24].

При изучении состава образцов ударнорасплавленных пород из скв. 5101-3 и террасовых отложений кратерного озера было вновь доказано их обогащение хромом, а также никелем и кобальтом [13]. Однако проведенные этими исследователями определения содержания в импактитах элементов платиновой группы и отношения ${ }^{187} \mathrm{Os} /{ }^{188} \mathrm{Os}$, послужили основанием для заключения о хондритовом составе ударника, образовавшего кратер Эльгыгытгын.

Возникшее противоречие в определении состава ударника картера Эльгыгытгын: ахондрит $[14,19,24]$ или обыкновенный хондрит [13], вероятно, было разрешено в работе [12] в результате изучения изотопии хрома и относительного содержания $\varepsilon^{54} \mathrm{Cr}$ в составе образца импактного стекла из кратера. В качестве вероятного ударника был предложен фрагмент астероида $F$-типа, выделенный на основании выпадения космического объекта в Алмахата Ситта (Almachata Sitta) в Судане, представляющего смесь из 70-80\% обломков уреилитов и $20-30 \%$ обломков энстатитовых хондритов и обыкновенных хондритов [12, 23].

Таким образом, хром является важнейшим элементом для определения состава ударника, образовавшего кратер Эльгыгытгын. Значительное обогащение расплавных импактитов кратера хромом за счет состава ударника установлено многими исследователями. В связи с этим, вероятным основным источником хрома при образовании хромферида послужило вещество кратерообразующего метеорита, а акцессорную минерализацию хромферида можно считать формой локализации привнесенного хрома в ударнорасплавленные породы кратера Эльгыгытгын. 


\section{ЛИТЕРАТУРА}

1. Гуров Е.П., Вальтер А.А., Гурова Е.П., Серебренников А.И. Взрывной метеоритный кратер Эльгыгытгын на Чукотке. Докл. АН СССР. 1978. 240, № 6. С. 1407-1410.

2. Гуров Е.П., Гурова Е.П. Геологическое строение и вещественный состав пород импактных структур. Киев: Наук. думка, 1991. 160 с.

3. Зоткин И.Т., Цветков В.И. Поиски метеоритных кратеров на Земле. Астроном. вестник. 1970. № 4. С. 55 -65.

4. Некрасов И.А., Раудонис П.А. Метеоритные кратеры. Природа. 1963. № 1. С. 102-104.

5. Новгородова М.И. Самородные металлы в гидротермальных рудах. М.: Наука, 1983. 287 с.

6. Новгородова М.И., Горшков А.И., Трубкин Н.В., Цепин А.И., Дмитриева М.Т. Новые природные интерметаллические соединения железа и хрома хромферид и ферхромид. Зап. Всес. минерал. об-ва. 1986. CXV, вып. 3. C. 355-360.

7. Обручев С.В. По горам и тундрам Чукотки. М.: Гос. изд-во геогр. лит-ры, 1957. 198 с.

8. Beliy V.F. Impactogenesis and volcanism of the El'gygytgyn depression. J. Petrology. 1998. 6, № 1. P. 86-99.

9. Belyi V.F. Impactite generation in the El'gygytgyn depression, Northeast Russia, as a volcanic fenomenon. 2. On the petrography and geochemistry of the impactites. J. Volcanol. Seismolog. 2010. № 4. P. 149-163.

10. Dietz R.S. El'gygytgyn crater, Siberia: probable source of Australasian tektite field (and besiadites from Popigai). Meteoritics. 1977. 12, № 2. P. 145-157.

11. Dietz R.S., McHone J.F. El'gygytgyn: probable world largest meteorite crater. Geology. 1976. 4, № 7. P. $391-392$.

12. Foriel J., Moynier F., Schulz T., Koeberl C. Chromium isotope anomaly in an impactite sample from the El'gygytgyn structure, Russia: Evidence for a ureilite projectile? Meteorit. and Planet. Sci. 2013. 48, № 7. P. 1339-1350.

13. Goderis S., Wittmann A., Zaiss J., Elburg M., Ravizza G., Vanhaecke F., Deutsch A., Claeys P. Testing the ureilite projectile hypothesis for the El'gygytgyn impact: Determination of siderophile element abundance and Os isotope ratios in ICDR drill core samples and melt rocks. Meteorit. and Planet. Sci. 2013. 48, № 7. P. 1296-1324.

14. Gurov E.P., Koeberl C. Shocked rocks and impact glasses from the El'gygytgyn impact structure, Russia. Meteorit. and Planet. Sci. 2004. 39, № 9. P. 1495-1508.

15. Gurov E.P., Koeberl C., Reimold W.U., Brandstatter F., Amare K. Shock metamorphism of siliceous volcanic rocks of the El'gygytgyn impact crater (Chukotka, Russia) In: Large meteorite impacts III, eds. Kenkmann T., Horz F. and Deutsch A. Geol. Soc. Amer. Spec. Paper. 2005. 348. P. 391-412.

16. Gurov E.P., Permiakov V.V., Koeberl C. Remnants of paleoflora in impact melt rocks of the El'gygytgyn crater (Chukotka, Russia). Meteorit. and Planet. Sci. (this is an open access), 2019. P. 1-9. doi: 10.1111/maps.13241

17. Gurov E.P., Valter A.A., Gurova E.P., Kotlovskaya F.I. El'gygytgyn impact crater, Chukotka: shock metamorphism of volcanic rocks. Lunar Planet. Sci. Conf. (abstracts). 1979. 10. P. 479-481.

18. Hawthorne F.C., Burke E.A.J., Ercit T.S., Grew E.S., Grice J.D., Jambor J.L., Puziewicz J., Roberts A.C., Vanko D.A. New mineral names. Amer. Miner. 1988. 73. P. 189-199.

19. Kapustkina I.G., Feldman V.I., Kolesov G.M. Behaviour of some meteoritic indicator elements in process of impact melt degassing. Lunar Planet. Sci. Conf. (abstracts). 1985. 16. P. 422.

20. Koeberl C., Pittarello L., Reimold W.U., Raschke U., Brigham-Grette J., Melles M., Minyuk M. El'gygytgyn impact crater, Chukotka, Arctic Russia: Impact cratering aspects of the 2009 ICDP drilling project. Meteorit. and Planet. Sci. 2013. 48, № 7. P. 1108-1129.

21. Layer P.V. ${ }^{40}$ Argon $/{ }^{39}$ Argon-age of the El'gygytgyn event, Chukotka, Russia. Meteorit. and Planet. Sci. 2000.35. P. 591-599.

22. Pittarello L., Koeberl C. Petrography of impact glasses and melt breccias from the El'gygytgyn structure, Russia. Meteorit. and Planet. Sci. 2013. 48, № 7. P. 1236-1250.

23. Shaddad M.H., Jenniskens P., Numan D., Kudoda A.M., Elsir S., Riyad I.F., Ali A.E., Alameen M., Alameen N.M., Eid O., Osman A.T., Abubaker M.I., Yosif M., Chesley S.R., Chodas P.W., Albers J., Edwarda W.N., Brown P.G., Kuiper J., Friedrich J.M. The recovery of asteroid 2008 TC $_{3}$. Meteorit. and Planet. Sci. 2010. 45. P. 1557-1589.

24. Val'ter A.A., Barchuk I.F., Bulkin V.S., Ogorodnic A.F., Kotishevskaya E.Y. The El'gygytgyn meteorite: Probable composition. Soviet Astronom. Lett. 1982. 8. P. 115-120.

Поступила 07.02.2019

\section{REFERENCES}

1. Gurov, E.P. and Gurova, E.P. (1991), Geological structure and rock composition of impact structures, Nauk. dumka, Kyiv, UA, 160 p.

2. Gurov, E.P., Valter, A.A., Gurova, E.P. and Serebrennikov, A.I. (1978), Doklady Acad. Nauk SSSR, Vol. 240, No. 6, RU, pp. 1407-1410.

3. Zotkin, I.T. and Tsvetkov, V.A. (1970), Astronomitcheskiy vestnik, No. 4, RU, pp. 55-65.

4. Nekrasov, I.A. and Raudonis, P.A. (1963), Priroda, No. 1, RU, pp. 102-104.

5. Novgorodova, M.I. (1983), Native metals in hydrothermal ores, Nauka, Moscow, RU, 287 p.

6. Novgorodova, M.I., Gorschkov, A.I., Trubkin, N.V., Tsepin, A.I. and Dmitrieva, M.T. (1986), Zap. Vsesoyuzn. Mineral. $o b-v a$, Vol. 115, No. 3, RU, pp. 355-360. 
7. Obruchev, S.V. (1957), Across the tundra and mountains of Chukotka, State Press of Geography, Moscow, RU, 198 p.

8. Belyi, V.F. (1998), J. Petrology, Vol. 6, No. 1, pp. 86-99.

9. Belyi, V.F. (2010), J. Volcanol. Seismol., No. 4, pp. 149-163.

10. Dietz, R.S. (1977), Meteoritics, Vol. 12, No. 2, pp. 145-157.

11. Dietz, R.S. and McHone, J.F. (1976), Geology, Vol. 4, No. 7, pp. 391-392.

12. Foriel, J., Moynier, F., Schulz, T. and Koeberl, C. (2013), Meteorit. and Planet. Sci., Vol. 48, No. 7, pp. $1339-1350$.

13. Goderis, S., Wittmann, A., Zaiss, J., Elburg, M., Ravizza, G., Vanhaecke, F., Deutsch, A. and Claeys, P. (2013), Meteorit. and Planet. Sci., Vol. 48, No. 7, pp. 1296-1324.

14. Gurov, E.P. and Koeberl, C. (2004), Meteorit. and Planet. Sci., Vol. 39, No. 9, pp. 1495-1508.

15. Gurov, E.P., Koeberl, C., Reimold, W.U., Brandstatter, F. and Amare, K. (2005), Large meteorite impacts III, eds. Kenkmann, T., Horz, F. and Deutsch, A. (2005), Geol. Soc. Amer. Spec. Pap., Vol. 348, pp. 391-412.

16. Gurov, E.P., Permiakov, V.V. and Koeberl, C. (2019), Meteorit. and Planet. Sci. (this is an open access), pp. 1-9. doi: 10.1111/maps. 13241

17. Gurov, E.P., Valter, A.A., Gurova, E.P. and Kotlovskaya, F.I. (1979), Lunar Planet. Sci. Conf. (abstracts), Vol. 10, pp. 479-481.

18. Hawthorne, F.C., Burke, E.A.J., Ercit, T.S., Grew, E.S., Grice, J.D., Jambor, J.L., Puziewicz, J., Roberts, A.C. and Vanko, D.A. (1988), Amer. Miner., Vol. 73, pp. 189-199.

19. Kapustkina, I.G., Feldman, V.I. and Kolesov, G.M. (1985), Lunar Planet. Sci. Conf. (abstracts), Vol. 16, p. 422.

20. Koeberl, C., Pittarello, L., Reimold, W.U., Raschke, U., Brigham-Grette, J., Melles, M. and Minyuk, M. (2013), Meteorit. and Planet. Sci., Vol. 48, No. 7, pp. 1108-1129.

21. Layer, P.V. (2000), Meteorit. and Planet. Sci., Vol. 35, pp. 591-599.

22. Pittarello, L. and Koeberl, C. (2013), Meteorit. and Planet. Sci., Vol. 48, No. 7, pp. 1236-1250.

23. Shaddad, M.H., Jenniskens, P., Numan, D., Kudoda, A.M., Elsir, S., Riyad, I.F., Ali, A.E., Alameen, M., Alameen, N.M., Eid, O., Osman, A.T., Abubaker, M.I., Yosif, M., Chesley, S.R., Chodas, P.W., Albers, J., Edwarda, W.N., Brown, P.G., Kuiper, J. and Friedrich, J.M. (2010), Meteorit. and Planet. Sci., Vol. 45, pp. 1557-1589.

24. Val'ter, A.A., Barchuk, I.F., Bulkin, V.S., Ogorodnic, A.F. and Kotishevskaya, E.Y. (1982), Soviet Astronom. Lett., Vol. 8 , pp. 115-120.

Received 07.02.2019

\section{С.П. Гуров, В.В. Пермяков}

Інститут геологічних наук НАН України

01601, м. Київ, Україна, вул. О. Гончара, 55-б

E-mail: yevgeniy.gurov@gmail.com; 0673866227@ukr.net

\section{ХРОМФЕРИД У РОЗПЛАВНИХ ІМПАКТИТАХ КРАТЕРА ЕЛЬГИГИТГИН (ЧУКОТКА, РФ)}

Хромферид установлено у складі ударнорозплавлених порід імпактного кратера Ельгигитгин. Ця структура діаметром 18 км утворена 3,6 млн рр. тому в товщі вулканічних порід крейдового віку центральної частини Чукотського півострова (РФ). Ударнорозплавлені породи, склуваті бомби та ударнометаморфізовані вулканічні породи мішені кратера на сучасному рівні ерозійного зрізу поширені у перевідкладеному стані у терасах озера Ельгигитгин, яке займає центральну частину кратерного басейну. Акцесорна мінералізація хромфериду встановлена за допомогою електронно-мікроскопічного дослідження ударнорозплавлених порід із озерної тераси в південній частині кратера. Вони представлені масивними пухирчастими породами зі склуватою матрицею та численними включеннями уламків ударнометаморфізованих порід і мінералів мішені кратера. Агрегати та зерна хромфериду кристалізувалися у контракційних тріщинах у склуватій матриці порід та на внутрішній поверхні газових пухирів. Контракційні тріщини товщиною до 10-12 мкм мають неправильну форму, іноді вони розгалужуються. Хромферид утворює зростки та окремі зерна у тріщинах. Іноді його агрегати розміром до 10 мкм заповнюють вузькі частини деяких тріщин. Друга форма локалізації хромфериду представлена у вигляді кристалізації на внутрішній поверхні газових пухирів. Деякі його зерна, що кристалізувалися у вільному просторі пухирів, мають пластинчасту структуру. Склад хромфериду з розплавних імпактитів відповідає кристалохімічній формулі: $\mathrm{Fe}_{3,0} \mathrm{Cr}_{0,4}$ або $\mathrm{Fe}_{1,5} \mathrm{Cr}_{0,2}$, зі співвідношенням $\mathrm{Fe} / \mathrm{Cr} \sim 7$. Кристалізація мінералу в контракційних тріщинах і у газових пухирях свідчить про його пізнє утворення після повного затвердіння ударнорозплавленої породи. Збагачення розплавних імпактитів та стекол хромом відносно вулканічних порід мішені кратера Ельгигитгин за рахунок речовини ударника було встановлено раніше у ході геохімічних досліджень, отже, ймовірним джерелом хрому під час утворення хромфериду була речовина кратероутворювального астероїда.

Ключові слова: Ельгигитгин, імпактний кратер, ударнорозплавлена порода, склувата матриця, газовий пухир, хромферид. 
Ye.P. Gurov, V.V. Permiakov

Institute of Geological Sciences of NAS of Ukraine

55-b, O. Honchara Str., Kyiv, Ukraine, 01601

E-mail: yevgeniy.gurov@gmail.com; 0673866227@ukr.net

CHROMFERIDE IN IMPACT MELT ROCKS

OF EL'GYGYTGYN CRATER (CHUKOTKA, RUSSIA)

Chromferide was discovered in impact melt rocks of the El'gygytgyn impact crater. This structure, $18 \mathrm{~km}$ in diameter, was formed 3.6 Ma ago in the sequence of cretaceous volcanic rocks in the central part of the Chukotka Peninsula (Russia). Impact melt rocks, glass bombs and shock-metamorphosed volcanic rocks of crater target at the recent erosional level occur in redeposited state in terraces of the El'gygytgyn Lake that occupies the central part of the crater basin. Accessory mineralization of chromferide was discovered by electron-microscopic investigations of impact melt rocks from the lacustrine terrace located in the southern part of the crater. These impactites are massive vesicular clast-rich rocks with partially devitrified glassy matrix and numerous clasts of shock-metamorphosed rocks and minerals. Aggregations and grains of chromferide occur in contraction cracks in rock matrix, and rarely on the inner surface of gas bubbles. Contraction cracks have irregular shape, sometimes they branch out. Chromferide forms intergrowths and separate grains in the cracks, some of its aggregations up to $10 \mu \mathrm{m}$ long completely fill narrow sections of cracks. The second form of chromferide localization is presented by its crystallization on the inner surface of gas bubbles. Some grains of chromferide have lamellar structure due to their formation in open space. Composition of chromferide corresponds to the $\mathrm{Fe}_{3.0} \mathrm{Cr}_{0.4}$ formula, or $\mathrm{Fe}_{1.5} \mathrm{Cr}_{0.2}$, and $\mathrm{Fe} / \mathrm{Cr}$ ratio is $\sim 7$. Occurrence of chromferide in contraction cracks and gas bubbles in impact melt rocks is an evidence of its late formation after complete solidification of impact melt rock. Enrichment of impact melt rocks and impact glasses in chromium in comparison with volcanic target rocks of El'gygytgyn crater was previously known from geochemical investigations. Thus, the probable source of chromium in chromferide was the matter of the crater-forming asteroid.

Keywords: El'gygytgyn impact crater, impact melt rock, glassy matrix, gas bubble, chromferide. 